\title{
Different fatty acid metabolism effects of (-)-Epigallocatechin-3-Gallate and C75 in Adenocarcinoma lung cancer
}

\author{
Joana Relat ${ }^{1 \dagger}$, Adriana Blancafort ${ }^{2 \dagger}$, Glòria Oliveras ${ }^{2,3}$, Sílvia Cufi ${ }^{3}$, Diego Haro ${ }^{1}$, Pedro F Marrero ${ }^{1}$ and Teresa Puig ${ }^{2^{*}}$
}

\begin{abstract}
Background: Fatty acid synthase (FASN) is overexpressed and hyperactivated in several human carcinomas, including lung cancer. We characterize and compare the anti-cancer effects of the FASN inhibitors C75 and (-)-epigallocatechin-3-gallate (EGCG) in a lung cancer model.

Methods: We evaluated in vitro the effects of C75 and EGCG on fatty acid metabolism (FASN and CPT enzymes), cellular proliferation, apoptosis and cell signaling (EGFR, ERK1/2, AKT and mTOR) in human A549 lung carcinoma cells. In vivo, we evaluated their anti-tumour activity and their effect on body weight in a mice model of human adenocarcinoma xenograft.

Results: C75 and EGCG had comparable effects in blocking FASN activity $(96,9 \%$ and $89,3 \%$ of inhibition, respectively). In contrast, EGCG had either no significant effect in CPT activity, the rate-limiting enzyme of fatty acid $\beta$-oxidation, while C75 stimulated CPT up to 130\%. Treating lung cancer cells with EGCG or C75 induced apoptosis and affected EGFR-signaling. While EGCG abolished p-EGFR, p-AKT, p-ERK1/2 and p-mTOR, C75 was less active in decreasing the levels of EGFR and p-AKT. In vivo, EGCG and C75 blocked the growth of lung cancer xenografts but C75 treatment, not EGCG, caused a marked animal weight loss.

Conclusions: In lung cancer, inhibition of FASN using EGCG can be achieved without parallel stimulation of fatty acid oxidation and this effect is related mainly to EGFR signaling pathway. EGCG reduce the growth of adenocarcinoma human lung cancer xenografts without inducing body weight loss. Taken together, EGCG may be a candidate for future pre-clinical development.
\end{abstract}

Keywords: Lung cancer, Xenograft, Fatty acid synthase, EGCG, C75, Inhibitors, Weight loss, Fatty acid metabolism, EGFR

\section{Background}

Fatty acid synthase (E.C.2.3.1.85; FASN) is a homodimeric multienzymatic protein that catalyzes de novo synthesis of long-chain fatty acids from acetyl-CoA, malonyl-CoA, and $\mathrm{NADPH}$ precursors [1]. In most human tissues the diet supplies the fatty acids needs and FASN expression is low or undetectable. In contrast, in many human solid carcinomas, lipogenic enzymes (mainly FASN) are highly expressed [2-7] and de novo fatty acids biosynthesis supplies the needs of long chain fatty acids (LCFA) for energy

\footnotetext{
*Correspondence: teresa.puig@udg.edu

${ }^{\dagger}$ Equal contributors

${ }^{2}$ Molecular Oncology (NEOMA), School of Medicine, University of Girona and Girona Institute for Biomedical Research (IDIBGi), 17071, Girona, Spain Full list of author information is available at the end of the article
}

production, protein acylation, synthesis of biological membranes, DNA synthesis and cell cycle progression among other biological processes, providing an advantage for tumour growth and progression [3-5].

FASN inhibition that blocks lipogenic pathway and impedes fatty acid synthesis, entails apoptosis in tumour cells that overexpress FASN, without affecting nonmalignant cells (reviewed in ref. [8]). In this context, FASN enzyme has became a promising target for anticancer therapy, a putative biomarker of malignancy and an indicative of prognosis for many cancers, including lung carcinomas [5-7,9].

The oncogenic properties of FASN seem to be the result of an increased activation of HER2 and its downstream

\section{Biomed Central}


signaling cascades: phosphoinositide-3 kinase/protein kinase $\mathrm{B} /$ mammalian target of rapamycin (PI3K/AKT/mTOR), mitogen-activated protein kinase/extracellular signalregulated kinase (MAPK/ERK1/2) pathways [10-18].

The use of FASN inhibition as anticancer therapy was first described with Cerulenin (a natural antibiotic from Cephalosporium ceruleans) that causes apoptotic cancer cell death in vitro [19]. More recently, C75, a synthetic analogue of cerulenin or (-)-epigallocatechin-3-gallate (EGCG), the main polyphenolic catechin of the green tea, have been identified as FASN inhibitors, able to induce apoptosis in several tumour cell lines and also to reduce the size of mammary tumours in animal models [8,20-24]. Although its selective cytotoxicity, C75 has been discarded in many cancer models due to its side effects: anorexia and body weight loss. In contrast, we have demonstrated that in SKBr3 breast cancer cells EGCG has similar effects as C75 in inhibiting FASN and it does not induce CPT activity in vitro, neither weight loss in vivo $[11,25,26]$, opening new perspectives in the use of green tea polyphenols or its derivatives as anti-cancer drugs alone or in combination with other therapies.

Here we compare the effects of C75 and EGCG on lipogenesis (FASN activity), fatty acid oxidation (CPT activity), cellular proliferation, induction of apoptosis and cell signaling (EGFR, ERK1/2, AKT and mTOR) in A549 lung carcinoma cells. We also evaluated their anti-cancer activity and their effect on body weight with a mice model of A549 lung cancer xenograft. We examined EGCG as a potential drug for clinical development in adenocarcinoma of lung cancer that accounts for $40 \%$ of non-small-cell lung cancers (NSCLC), the most common type of lung cancer [27].

\section{Methods}

\section{Cell Lines and Cell Culture}

A549 lung cancer cells were obtained from the American Type Culture Collection (ATCC, Rockville, MD, USA), and were cultured in Dulbecco's Modified Eagle's Medium (DMEM, Gibco, Berlin, Germany) containing $10 \%$ heat-inactivated fetal bovine serum (FBS, HyClone Laboratories, Utah, USA), 1\% L-glutamine, 1\% sodium pyruvate, $50 \mathrm{U} / \mathrm{mL}$ penicillin, and $50 \mu \mathrm{g} / \mathrm{mL}$ streptomycin (Gibco). Cells were routinely incubated at $37{ }^{\circ} \mathrm{C}$ in a humidified atmosphere of $95 \%$ air and $5 \% \mathrm{CO}_{2}$.

\section{Growth Inhibition Assay}

EGCG, C75 and 3-4,5-dimethylthiazol-2-yl-2,5-diphenyltetrazolium bromide (MTT) were purchased from Sigma-Aldrich (St. Louis, MO, USA). Dose-response studies were done using a standard colorimetric MTT reduction assay. Briefly, cells were plated out at a density of $3 \times 10^{3}$ cells/100 $\mu \mathrm{L} /$ well in 96-well microtiter plates. Following overnight cell adherence fresh medium along with the corresponding concentrations of EGCG and C75 were added to the culture. Following treatment, media was replaced by drug-free medium $(100 \mu \mathrm{L} /$ well $)$ and MTT solution $(10 \mu \mathrm{L}$ of a $5 \mathrm{mg} / \mathrm{mL})$, and incubation was prolonged for $2,5 \mathrm{~h}$ at $37^{\circ} \mathrm{C}$. After carefully removing the supernatants, the MTT-formazan crystals formed by metabolically viable cells were dissolved in DMSO (100 $\mu \mathrm{L} /$ well) and absorbance was determined at $570 \mathrm{~nm}$ in a multi-well plate reader (Spectra max 340PC (380), BioNova Cientifica s.l., Madrid, Spain). Using control optical density $\mathrm{OD}$ values $\left(\mathrm{OD}_{\mathrm{CTRL}}\right)$ and test $\mathrm{OD}$ values $\left(\mathrm{OD}_{\mathrm{T} \text { - }}\right.$ EST), the agent concentration that caused $50 \%$ growth inhibition ( $\mathrm{IC}_{50}$ value) was calculated from extrapolating in the trend line obtained by the formula $\left(\mathrm{OD}_{\mathrm{CTRL}}-\mathrm{OD}_{\mathrm{T}}\right.$ EST)*100/OD ${ }_{\text {CTRL. }}$.

\section{Fatty Acid Synthase Activity Assay}

Cells were plated out at a density of $1 \times 10^{5}$ cells/500 $\mu \mathrm{L} /$ well in 24-well microtiter plates. Following overnight cell adherence media was replaced by DMEM supplemented with 1\% lipoprotein deficient Fetal Bovine Serum (Sigma) along with the corresponding $\mathrm{IC}_{50}$ concentrations of $\mathrm{C} 75$ $(72 \mu \mathrm{M})$ and EGCG $(265 \mu \mathrm{M})$ or DMSO. For the last $6 \mathrm{~h}$ of the treatment, $\left(\left[1,2-{ }^{14} \mathrm{C}\right]\right.$ Acetic Acid Sodium salt (53,9 $\mathrm{mCi} / \mathrm{mmol}$ ) (Perkin Elmer Biosciences, Waltham, MA, USA) was added to the media $(1 \mu \mathrm{Ci} / \mathrm{mL})$. Cells were harvested and washed twice with phosphate-buffered saline (PBS) $(500 \mu \mathrm{L})$ and once with Methanol:PBS (2:3) $(500 \mu \mathrm{L})$. The pellet was resuspended in $0,2 \mathrm{M} \mathrm{NaCl}(100$ $\mu \mathrm{L})$ and broke with freeze-thaw cycles. Lipids from cell debris were extracted by centrifugation (2000 g, $5 \mathrm{~min}$ ) with Chloroform:Phenol $(2: 1)(350 \mu \mathrm{L})$ and $\mathrm{KOH} \mathrm{0,1} \mathrm{M}$ $(25 \mu \mathrm{L})$. The organic phase recovered is then washed with Chloroform:Methanol:Water (3:48:47) $(100 \mu \mathrm{L})$ and evaporated in a Speed-vac plus SC110A (Savant). The drypellets were resuspended in ethanol and transferred to a vial for radioactive counting.

\section{Mitochondria Isolation of A549 Cells}

Cells were grown to confluence in $10 \mathrm{~mm}$ dishes and collected in PBS (100 $\mu \mathrm{L} /$ dish). The pellet was resuspended in Buffer A (150 mM KCl, 5 mM Tris-HCl, pH 7.2) $(125 \mu \mathrm{L} /$ dish), and disrupted using a glass homogenizer (10 cycles with tight fitting pestle and 10 cycles with light one). Mitochondria were collected by centrifugation (16000 g, $5 \mathrm{~min}$ at $4^{\circ} \mathrm{C}$ ), resuspended in Buffer $\mathrm{A}$ and quantified using Bradford-based Bio-Rad assay (BioRad Laboratories, Hercules, CA, USA). At this step mitochondria could be used for total CPT activity measurement.

\section{Carnitine Palmitoyltransferase (CPT) Activity Assay}

CPT activity was assayed by the forward exchange method using L- $\left[\right.$ methyl $\left.-{ }^{3} \mathrm{H}\right]$ Carnitine hydrochloride $(82 \mathrm{Ci} /$ $\mathrm{mmol}$ ) (Perkin Elmer Biosciences) as we previously 
described [25]. Briefly, reactions (were performed in the standard enzyme assay mixture $\left(1 \mathrm{mM} \mathrm{L}-\left[{ }^{3} \mathrm{H}\right]\right.$ carnitine $(\sim 5000 \mathrm{dpm} / \mathrm{nmol}), 80 \mu \mathrm{M}$ palmitoyl-CoA (Sigma), 20 mM HEPES (pH 7.0), 1\% fatty acid-free albumin (Roche Sciences, Mannheim, Germany), 40-75 mM KCl and the corresponding $\mathrm{IC}_{50}$ concentrations of $\mathrm{C} 75$ $(72 \mu \mathrm{M})$ and EGCG $(265 \mu \mathrm{M})$ or DMSO when indicated. Reactions were initiated by addition of A549 isolated mitochondria $(100 \mu \mathrm{g})$ and all incubations were done at $30^{\circ} \mathrm{C}$ for $3 \mathrm{~min}$. Reactions were stopped by addition of $6 \%$ Perchloric Acid and then the product $\left[{ }^{3} \mathrm{H}\right]$-palmitoylcarnitine was extracted with butanol at low $\mathrm{pH}$ and was transferred to a vial for radioactive counting.

\section{Western Blot Analysis of Tumour and Cell Lysates}

The primary mouse monoclonal antibody for FASN was from Assay designs (Ann Arbor, MI, USA). Monoclonal anti- $\beta$-actin mouse antibody (clone AC-15) was from Santa Cruz Biotechnology Inc. (Santa Cruz, CA, USA). Rabbit polyclonal antibodies against poly-(ADP-ribose)-

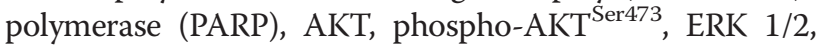
EGFR, phospho-EGFR ${ }^{\text {Tyr1068, }}$ mTOR, phospho-mTORSer2448 and mouse monoclonal antibody against phospho-

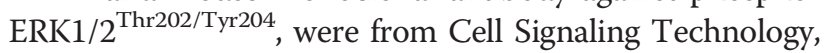
Inc (Danvers, MA, USA). A549 cells were harvested following treatment of A549 cells with EGCG or C75. Tumour tissues were collected from A549 human lung cancer xenografts at the end of the in vivo experiment. Cells and tumour tissues were lysed with ice-cold in lysis buffer (Cell Signaling Technology, Inc.) containing $1 \mathrm{mM}$ EDTA, $150 \mathrm{mM} \mathrm{NaCl}, 100 \mu \mathrm{g} / \mathrm{mL}$ PMSF, $50 \mathrm{mM}$ Tris$\mathrm{HCl}$ ( $\mathrm{pH}$ 7.5), protease and phosphatase inhibitor cocktails (Sigma). Protein content was determined by the Lowrybased Bio-Rad assay (BioRad Laboratories). Equal amounts of protein were heated in LDS Sample Buffer and Sample Reducing Agent from Invitrogen (California, USA) for $10 \mathrm{~min}$ at $70^{\circ} \mathrm{C}$, separated on $3 \%$ to $8 \%$ or $4 \%$ to $12 \%$ SDSpolyacrylamide gel (SDS-PAGE) and transferred to nitrocellulose membranes. After blocking, membranes were incubated overnight at $4^{\circ} \mathrm{C}$ with the corresponding primary antibody. Blots were washed in PBS-Tween, incubated for 1 hour with corresponding peroxidase-conjugated secondary antibody and revealed using a commercial kit (Super Signal West Pico or Super Signal West Femto chemiluminescent substrate from Thermo scientific (Illinois, USA) or Immobilon Western HRP Substrate from Millipore (Massachusetts, USA)). Blots were re-proved with an antibody against $\beta$ actin as control of protein loading and transfer.

In vivo Studies: Human Lung Tumour Xenograft and Longterm Weight Loss Experiments

Experiments were conducted in accordance with guidelines on animal care and use established by Biomedical Research Institute of Bellvitge (IDIBELL) Institutional
Animal Care and Scientific Committee (AAALAC unit 1155). Tumour xenograft were established by subcutaneous injection of $10 \times 10^{6}$ A549 cells mixed in Matrigel (BD Bioscience, California, USA) into 4-5 week old athymic nude BALB/c female's flank (Harlan Laboratories, Gannat, France). Female mice A549 (12 wk, 23-25 g) were fed ad libitum with a standard rodent chow and housed in a light/dark $12 \mathrm{~h} / 12 \mathrm{~h}$ cycle at $22^{\circ} \mathrm{C}$ in a pathogen-free facility. Animals were randomized into three groups of five animals in the control and four animals in the C75 and EGCG-treated groups. When tumours' volume were palpable (reached around $35-40 \mathrm{~mm}^{3}$ ) each experimental group received an i.p. injection once a week of C75 or EGCG inhibitor $(40 \mathrm{mg} / \mathrm{kg}$ ) or vehicle alone (DMSO), dissolved in RPMI 1640 medium. Tumour volumes and body weight were registered the days of treatment and four days after every treatment until 33 days after first administration. Tumours were measured with electronic calipers, and tumour volumes were calculated by the formula: $\pi / 6 \times(\mathrm{v} 1 \times \mathrm{v} 2 \times \mathrm{v} 2)$, where $\mathrm{v} 1$ represents the largest tumour diameter, and v2 the smallest one. At the end of the experiment, all mice were euthanized and tumour tissues were collected.

\section{Statistical Analysis}

In vitro results were analysed by Student's $t$-test or by one-way ANOVA using a Bonferroni test as a post-test. All data are mean \pm standard error (SE). All observations were confirmed by at least three independent experiments. In vivo drug efficacy experiment results were analyzed using the non-parametric Wilcoxon test comparing repeated measurements (tumour volume). Data are the median of tumour volume of 4 or 5 animals. Statistical significant levels were $\mathrm{p}<0.05$ (denoted as *) and $\mathrm{p}<0,001$ (denoted as $*$ ).

\section{Results}

\section{Effect of EGCG and C75 on FASN and CPT Activities in A549 Cells}

In order to evaluate the specificity of EGCG and C75 for FASN, we analyzed their effect on FASN and CPT system activities. A549 cells were treated for 24 hours with $\mathrm{IC}_{50}$ concentration values of C75 $(72 \pm 2,8 \mu \mathrm{M})$ or EGCG $(265 \pm 7,1 \mu \mathrm{M})$ [Additional file 1: Figure S1]. As shown in Figure 1, C75 and EGCG significantly reduced FASN activity in A549 cells compared to control cells (remaining FASN activity of $3,1 \pm 0,6 \%$ and $10,7 \pm 1,5 \%, p=0,000$; both). Significant changes in FASN protein levels were also observed in EGCG-treated cells but not in control or C75-treated cells, as assessed by Western blotting (Figure 2). The effect of both compounds on CPT enzymatic activity was assayed in A549 isolated mitochondria, as described in the Material and Methods section. EGCG had no effect on CPT activity $(115 \pm 12 \%$, respect 
to control; $\mathrm{p}=0,006)$, in contrast to $\mathrm{C} 75$, which produced a significant activation of CPT system $(131 \pm 11 \%$, respect to control; $\mathrm{p}=0,294)$.

\section{Analysis of the Effect of EGCG and C75 on Apoptosis and Cell Signaling in A549 Cells}

Apoptosis and induction of caspase activity were checked with cleavage of PARP in Western blotting analysis. Apoptosis was not detected in A549 non-treated cells. In A549 cells treated for 6, 12 and 24 hours with $\mathrm{IC}_{50}$ concentration values of $\mathrm{C75}$ or EGCG (Additional file 1: Figure S1), there was an increase in the levels of $89 \mathrm{kDa}$ PARP product in a time-dependent manner (Figure 3). We examined the effects of EGCG and C75 on the phosphorylated and the total levels of EGFR (p-EGFR), HER2 (p-HER2), HER3 (p-HER3), HER4 (p-HER4) and its related downstream AKT, ERK1/2 and mTOR proteins. Results in Figure 3 confirmed that A549 cells treated with EGCG showed a marked decrease in the phosphorylated forms of EGFR, AKT, ERK1/2 and mTOR within 6 hours of EGCG treatment, with no changes in the total levels of the corresponding proteins. In contrast, C75 treatment needs up to 48 hours just to detect a partial decrease on total levels of EGFR protein and on $\mathrm{p}$ AKT protein. Phosphorylated and total protein levels of HER2 (p-HER2), HER3 (p-HER3) and HER4 (p-HER4) did not change after C75- or EGCG-treatment (Data not shown).

\section{In Vivo Analysis of EGCG and C75 on Human Lung Cancer Xenografts}

To explore the potential effectiveness of EGCG and C75 for lung cancer treatment in vivo, we treated athymic nude mice with A549 human lung cancer xenograft. In control animals, on final day the median of the tumour volume (519 $\mathrm{mm}^{3}$ on day 33) was significantly different from the starting median tumour volume $\left(33 \mathrm{~mm}^{3}\right.$ on day $0, \mathrm{p}=0,04$ ) and this trend (was similar from days 12 to 33 in control animals' group (Data not shown). In the experimental animals, the median of the tumour volume of C75- and EGCG-treated animals on day 33 (290 and $224 \mathrm{~mm}^{3}$, respectively) wasn't significantly different from the median of the tumour volume on the starting day (40 and $36 \mathrm{~mm}^{3}$, respectively; $\mathrm{p}=0,07$ both), those pointing out that the treatment with the anti-FASN compounds C75 and EGCG prevents the growth of A549 xenografts (Figure 4A). C75 and EGCG-treated tumours showed apoptosis by induction of PARP cleavage without any change in the total levels of FASN protein (Figure 4A). In EGCG-treated animals we do not find significant changes on fluid, food intake, body weight or other toxicity parameters (data not shown) versus control animals, after 33 days of weekly treatment with $40 \mathrm{mg} / \mathrm{Kg}$ of EGCG (Figure 4B). C75-treated animals showed a marked decrease of body weight (close to 6\%) after each i.p. administration, which was especially remarkable in the first 20 days of treatment (Figure 4B).

\section{Discussion}

Levels of FASN expression in different human carcinomas attracted considerable interest of this enzyme as a target for therapy $[10,11]$. In this study, we show that adenocarcinoma of lung cancer, is among the foremost of cancers that could potentially be treated by inhibiting FASN.

C75 has been studied in A549 lung cancer xenografts [28] where it induces a transient and reversible growth inhibition. EGCG anti-cancer effects in lung cancer have

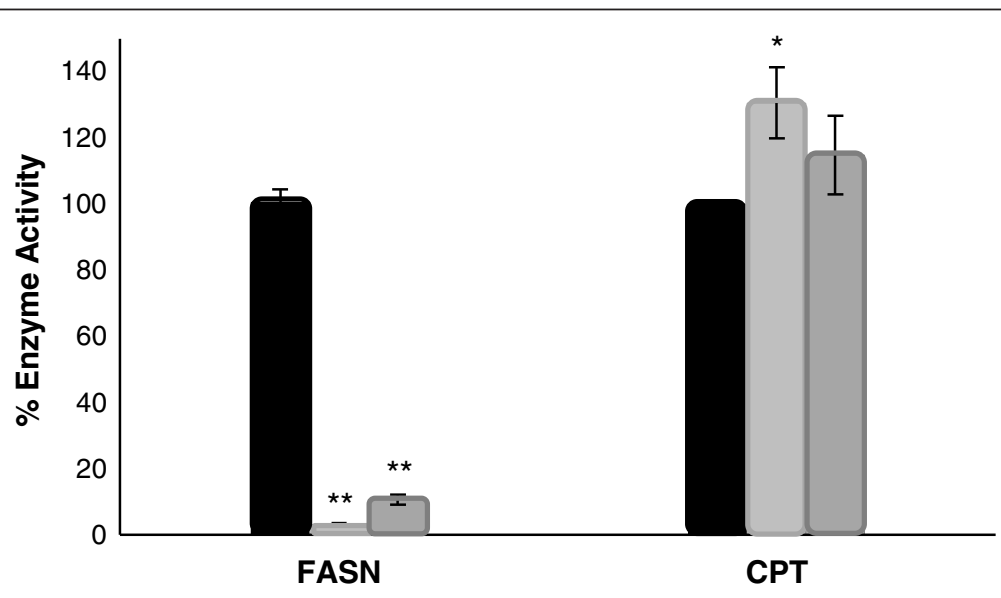

Figure 1 EGCG inhibits FASN activity in A549 cancer cells with no change on CPT system activity. A549 Cells were treated for 24 hours with C75 $(72 \mu \mathrm{M})$ and EGCG $(265 \mu \mathrm{M})$ and FASN activity was assayed by counting radiolabelled fatty acids synthesized de novo. Isolated mitochondria from A549 cells were assayed for CPT activity in the presence of DMSO (control), C75 (72 $\mu \mathrm{M})$ or EGCG (265 $\mu \mathrm{M})$ ), as described in Material and Methods. Bars represent the remaining enzyme activity in A549 treated cells or mitochondria. Data are means \pm SE from at least 3 separate experiments. ${ }^{* *} p<0,001$ versus control, by one-way ANOVA or Student's t-test. 


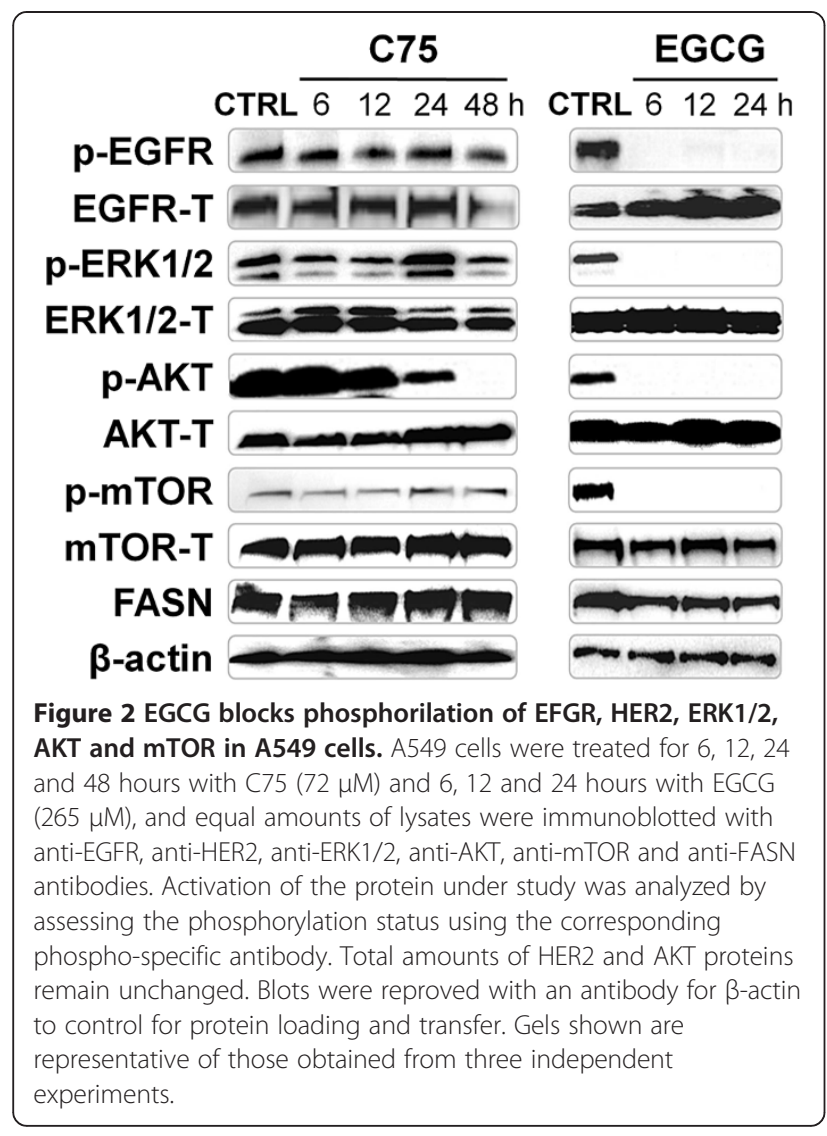

also been evidenced and, besides FASN-inhibition, several mechanisms of action have been proposed, such as G3BP1 (GTPase activating protein (SH3 domain) binding protein) inhibition [29], generation of Reactive Oxygen Species (ROS) [30] or induction of p53-dependent transcription [31].

To further investigate the implications of FASN inhibition in lung adenocarcinoma, we have analyzed the blockage of FASN by EGCG and C75 in A549 lung cancer cells. Firstly, we ensured similar levels of FASN inhibition by C75- and EGCG-treatment (96,9\% and 89,3\%

Figure 3 EGCG and C75 induce apoptosis in A549 cells.
Induction of caspase activity was confirmed by PARP cleavage. A549
cells were treated with C75 (72 $\mu \mathrm{M})$ or EGCG (265 $\mu \mathrm{M}$ ) for 6 , 12 and
24 hours, and equal amounts of lysates were immunoblotted with
anti-PARP antibody, which identified the 89 kDa (cleavage product)
band. Blots were reproved for $\beta$-actin as loading control. Gels shown
are representative of those obtained from three independent
experiments.

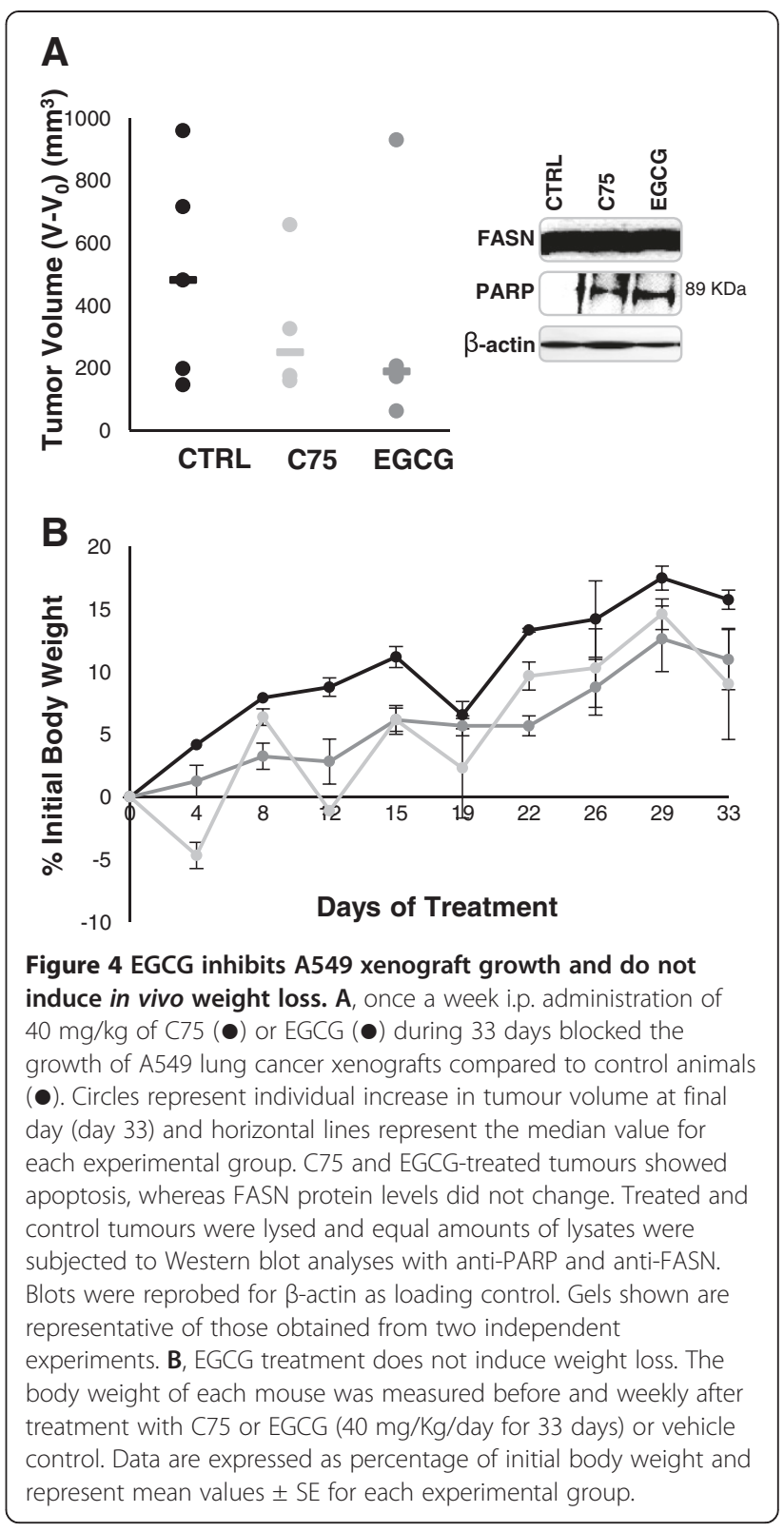

of control, respectively). As $\mathrm{C} 75$ had no effect on the abundance of FASN protein levels and EGCG diminished the levels of this enzyme, it is probable that in the EGCG-treated cells, the reduction of FASN activity could be in part consequence of the reduced FASN protein levels.

The inhibition of FASN activity by EGCG and C75 was accompanied by an induction of apoptosis, and changes in cell growth and proliferation signaling pathways. The active phosphorylated form of EGFR (p-EGFR) was completely abolished after 6 hours of exposure to EGCG. Consequently, phosphorylated forms of ERK1/2 (p-ERK1/2), AKT (p-AKT) and mTOR (p-mTOR) were also markedly decreased. It is remarkable that 
comparable concentrations of $\mathrm{C} 75$, even with prolonged exposure (48 hours), only partially decreased total levels of EGFR and phosphorylated levels of AKT (p-AKT). Several data supported a relationship between HER2 and FASN in breast cancer, head and neck carcinomas, HER2-overexpressed fibroblasts and other carcinomas [11,32-35]. Furthermore, some authors have demonstrated the blocking effects of the FASN inhibitor EGCG on all members of epidermal growth factor receptor (ErbB) family [11,36-38].

This is the first evidence that EGFR is involved in the regulation of FASN expression in a lung cancer model with EGFR-overexpression. EGFR may be another EGCG-direct target that through inhibition of its downstream signalers (Akt, ERK1/2 and mTOR) is able to down-regulate FASN expression at two different levels: 1 , at the transcriptional level through the sterol response element-binding proteins 1c (SREBP-1c), the FASNtranscription factor mediated by PI3K/Akt and MAPK/ ERK1/2 pathways [39]; 2, at the translational level, through Akt-mTOR-signaling and its downstream effectors, eIF4G and S6K (reviewed in ref [40]) as seen in breast cancer [41] and in human hepatoma cells [42].

In addition, we corroborate a FASN-ErbB loop, described in breast cancer. The FASN disruption impedes synthesis of lipids, which are integrated in membrane lipid raft in which cell surface receptors, ErbB among others, accommodate and sense to tumourigenic pathways [43]. C75 is a direct and competitive inhibitor of FASN [21]. Consequently, we have seen a strong and fast inhibition of FASN activity with C75 treatment and a later effect on levels of EGFR and phosphorylation of it downstream effector Akt (p-Akt), what brings us to corroborate the idea of a FASN-lipid rafts-ErbB inhibition loop.

An important result of our study is the in vivo drugefficacy study and long-term body weight evaluation. EGCG and C75 markedly blocked the growth of A549 lung cancer xenografts while the tumour volumes of control animals growth significantly until the final day study. C75-treated mice showed a marked decrease in body weight after each administration (close to 6\% of initial body weight). This result accords to the data that C75 is able to stimulate CPT system and fatty acid $\beta$-oxidation, which has been related to the severe decrease of food intake and induction of weight loss in rodents [44]. In contrast, we have not observed a significant decrease in body weight in the animals treated for 33 days with EGCG.

A key feature of EGCG is that does not affect CPT activity (as it is shown in vitro in Figure 1) and, consequently, it does not induce weight loss in experimental animals. This result in a lung cancer model are in agreement with our previous findings in a mouse breast cancer model [11] and reinforces the hypothesis that CPT- activation is the cause of weight loss in xenografts models. Our data also reveal for the first time that the effects of EGCG in lung carcinoma involve different pathways than $\mathrm{C} 75$ but also that the undesirable side effects observed in C75 treated-mice are not produced in EGCG-treated mice.

\section{Conclusions}

In conclusion, the work reported here supports the development of EGCG as a FASN inhibitor for adenocarcinoma lung cancer treatment. EGCG acts as potent and lipogenic-selective inhibitor of FASN, and do no exhibit adverse effects on body weight, therefore holding promise for further target-directed anti-cancer drug studies either alone or co-administered with other antitumoural drugs.

\section{Additional file}

Additional file 1: Figure S1. EGCG and C75 show cytotoxic activity in A549 human lung carcinoma cells. A549 cells were treated with different concentrations of C75 $(20-200 \mu \mathrm{M})$ or EGCG $(40-300 \mu \mathrm{M})$ for 48 hours. Pale gray $(\bullet)$ and dark grey $(\bullet)$ circles represent the percentage of A549 cell proliferation inhibition after C75 and EGCG treatment respectively, which was determined using an MTT assay. Results are expressed as mean percentage of inhibition in cell proliferation from three independent experiments performed in triplicate \pm SE. PDF File Format.

\section{Abbreviation}

FASN: inhibition in lung cancer

\section{Competing interests}

None of the authors has any potential conflict of interest regarding this work.

\section{Authors' contributions}

JR carried out the activity assays, participated in the design of the study, performed the statistical analysis and drafted the manuscript. AB carried out the immunoassays, performed the statistical analysis and drafted the manuscript. GO carried out the immunoassays. SC carried out the in vivo assays. TP conceived of the study and drafted the manuscript. TP, DH and PM participated in the design and coordination of the study. All authors have approved the final version of the manuscript.

\section{Acknowledgements}

Financial support was provided by the Spanish Instituto de Salud Carlos III (FIS PI082031, and PI1 100692 TP), the Spanish Ministerio de Ciencia e Innovación (MICCIN, CIT-090000-2008-10, TP), the Spanish Ministerio de Educación y Ciencia (SAF2010-15217, DH), the Catalan government (Ajut de Suport als Grups de Recerca de Catalunya Grants 2009SGR163, DH) and the Spanish Society of Medical Oncology (SEOM08, I. Juez and TP). The Catalan Agency for Grants in Research and Universities (AGAUR) and the European Social Funds (FSE) awarded SC with an FPI predoctoral grant and the University of Girona awared AB with a predoctoral grant. This work was also supported by the Red Temática de Investigación Cooperativa en Cáncer of the ISCIII (RTICC; RD06-0020-0028), Spanish Ministry of Science and Innovation \& European Regional Development Fund (ERDF).

\section{Author details}

${ }^{1}$ Biochemistry and Molecular Biology, School of Pharmacy and Institute of Biomedicine of the University of Barcelona (IBUB), 08028, Barcelona, Spain. ${ }^{2}$ Molecular Oncology (NEOMA), School of Medicine, University of Girona and Girona Institute for Biomedical Research (IDIBGi), 17071, Girona, Spain.

${ }^{3}$ Molecular Oncology, Catalan Institute of Oncology (ICO), Girona Institute for Biomedical Research (IDIBGi), 17007, Girona, Spain. 
Received: 11 November 2011 Accepted: 2 July 2012

Published: 6 July 2012

\section{References}

1. Smith S: The animal fatty acid synthase: one gene, one polypeptide, seven enzymes. FASEB J 1994, 8(15):1248-1259.

2. Kuhajda FP: Fatty-acid synthase and human cancer: new perspectives on its role in tumor biology. Nutrition 2000, 16(3):202-208.

3. Kuhajda FP: Fatty acid synthase and cancer: new application of an old pathway. Cancer Res 2006, 66(12):5977-5980

4. Menendez JA, Lupu R: Fatty acid synthase and the lipogenic phenotype in cancer pathogenesis. Nat Rev Cancer 2007, 7(10):763-777.

5. Milgraum LZ, Witters LA, Pasternack GR, Kuhajda FP: Enzymes of the fatty acid synthesis pathway are highly expressed in in situ breast carcinoma. Clin Cancer Res 1997, 3(11):2115-2120.

6. Swinnen JV, Roskams T, Joniau S, Van Poppel H, Oyen R, Baert L, Heyns W, Verhoeven G: Overexpression of fatty acid synthase is an early and common event in the development of prostate cancer. Int J Cancer 2002, 98(1):19-22.

7. Piyathilake CJ, Frost AR, Manne U, Bell WC, Weiss H, Heimburger DC, Grizzle WE: The expression of fatty acid synthase (FASE) is an early event in the development and progression of squamous cell carcinoma of the lung. Hum Pathol 2000, 31(9):1068-1073.

8. Relat J, Puig T: Design of Anti-Fasn Molecules as a New Anti-Tumour Modality. In Frontiers in Drug Design \& Discovery, Volume 5. Publishers BS.; 2010.

9. Visca P, Sebastiani V, Botti C, Diodoro MG, Lasagni RP, Romagnoli F, Brenna A, De Joannon BC, Donnorso RP, Lombardi G, et al: Fatty acid synthase (FAS) is a marker of increased risk of recurrence in lung carcinoma. Anticancer Res 2004, 24(6):4169-4173.

10. Puig T, Turrado C, Benhamú B, Aguilar H, Relat J, Ortega-Gutiérrez S, Casals G, Marrero PF, Urruticoechea A, Haro D, et al: Novel Inhibitors of Fatty Acid Synthase with Anticancer Activity. Clin Cancer Res 2009, 15(24):7608-7615.

11. Puig T, Vázquez-Martín A, Relat J, Pétriz J, Menéndez JA, Porta R, Casals G, Marrero PF, Haro D, Brunet J, et al: Fatty acid metabolism in breast cancer cells: differential inhibitory effects of epigallocatechin gallate (EGCG) and C75. Breast Canc Res Treat 2008, 109(3):471-479.

12. Van de Sande T, De Schrijver E, Heyns W, Verhoeven G, Swinnen JV: Role of the phosphatidylinositol 3'-kinase/PTEN/Akt kinase pathway in the overexpression of fatty acid synthase in LNCaP prostate cancer cells. Cancer Res 2002, 62(3):642-646.

13. Menendez JA, Mehmi I, Atlas E, Colomer R, Lupu R: Novel signaling molecules implicated in tumor-associated fatty acid synthase-dependent breast cancer cell proliferation and survival: Role of exogenous dietary fatty acids, p53-p21WAF1/CIP1, ERK1/2 MAPK, p27KIP1, BRCA1, and NF-kappaB. Int J Oncol 2004, 24(3):591-608.

14. Yoon S, Lee MY, Park SW, Moon JS, Koh YK, Ahn YH, Park BW, Kim KS: Up-regulation of acetyl-CoA carboxylase alpha and fatty acid synthase by human epidermal growth factor receptor 2 at the translational level in breast cancer cells. J Biol Chem 2007, 282(36):26122-26131.

15. Vazquez-Martin A, Colomer R, Brunet J, Lupu R, Menendez JA: Overexpression of fatty acid synthase gene activates HER1/HER2 tyrosine kinase receptors in human breast epithelial cells. Cell Prolif 2008, 41(1):5985.

16. Grunt TW, Wagner R, Grusch M, Berger W, Singer CF, Marian B, Zielinski CC, Lupu R: Interaction between fatty acid synthase- and ErbB-systems in ovarian cancer cells. Biochem Biophys Res Commun 2009, 385(3):454459

17. Shaw RJ: Glucose metabolism and cancer. Curr Opin Cell Biol 2006, 18(6):598-608.

18. Kim K, Kim HY, Cho HK, Kim KH, Cheong J: The SDF-1alpha/CXCR4 axis induces the expression of fatty acid synthase via sterol regulatory element-binding protein-1 activation in cancer cells. Carcinogenesis 2010, 31(4):679-686.

19. Vance D, Goldberg I, Mitsuhashi O, Bloch K: Inhibition of fatty acid synthetases by the antibiotic cerulenin. Biochem Biophys Res Commun 1972, 48(3):649-656.

20. Zhao W, Kridel S, Thorburn A, Kooshki M, Little J, Hebbar S, Robbins M: Fatty acid synthase: a novel target for antiglioma therapy. Br J Cancer 2006, 95 (7):869-878.
21. Kuhajda FP, Pizer ES, Li JN, Mani NS, Frehywot GL, Townsend CA: Synthesis and antitumor activity of an inhibitor of fatty acid synthase. Proc Natl Acad Sci U S A 2000, 97(7):3450-3454.

22. Vergote D, Cren-Olivé C, Chopin V, Toillon RA, Rolando C, Hondermarck H, Le Bourhis X: (-)-Epigallocatechin (EGC) of green tea induces apoptosis of human breast cancer cells but not of their normal counterparts. Breast Canc Res Treat 2002, 76(3):195-201.

23. Wang $X$, Tian W: Green tea epigallocatechin gallate: a natural inhibitor of fatty-acid synthase. Biochem Biophys Res Commun 2001, 288(5):1200-1206.

24. Brusselmans K, De Schrijver E, Heyns W, Verhoeven G, Swinnen JV: Epigallocatechin-3-gallate is a potent natural inhibitor of fatty acid synthase in intact cells and selectively induces apoptosis in prostate cancer cells. Int J Cancer 2003, 106(6):856-862.

25. Nicot C, Napal L, Relat J, González S, Llebaria A, Woldegiorgis G, Marrero PF, Haro D: C75 activates malonyl-CoA sensitive and insensitive components of the CPT system. Biochem Biophys Res Commun 2004, 325(3):660-664.

26. Puig T, Relat J, Marrero PF, Haro D, Brunet J, Colomer R: Green tea catechin inhibits fatty acid synthase without stimulating carnitine palmitoyltransferase- 1 or inducing weight loss in experimental animals. Anticancer Res 2008, 28(6A):3671-3676.

27. Jemal A, Bray F, Center MM, Ferlay J, Ward E, Forman D: Global cancer statistics. CA Cancer J Clin 2011, 61(2):69-90.

28. Lee JS, Orita H, Gabrielson K, Alvey S, Hagemann RL, Kuhajda FP, Gabrielson E, Pomper MG: FDG-PET for pharmacodynamic assessment of the fatty acid synthase inhibitor C75 in an experimental model of lung cancer. Pharm Res 2007, 24(6):1202-1207.

29. Shim JH, Su ZY, Chae Jl, Kim DJ, Zhu F, Ma WY, Bode AM, Yang CS, Dong Z: Epigallocatechin gallate suppresses lung cancer cell growth through RasGTPase-activating protein SH3 domain-binding protein 1. Canc Prev Res Phila 2010, 3(5):670-679.

30. Li GX, Chen YK, Hou Z, Xiao H, Jin H, Lu G, Lee MJ, Liu B, Guan F, Yang Z, et al: Pro-oxidative activities and dose-response relationship of (-)-epigallocatechin-3-gallate in the inhibition of lung cancer cell growth: a comparative study in vivo and in vitro. Carcinogenesis 2010, 31(5):902-910.

31. Yamauchi R, Sasaki K, Yoshida K: Identification of epigallocatechin-3-gallate in green tea polyphenols as a potent inducer of p53-dependent apoptosis in the human lung cancer cell line A549. Toxicol Vitro 2009, 23(5):834-839.

32. Kumar-Sinha C, Ignatoski KW, Lippman ME, Ethier SP, Chinnaiyan AM: Transcriptome analysis of HER2 reveals a molecular connection to fatty acid synthesis. Cancer Res 2003, 63(1):132-139.

33. Menendez JA, Lupu R: Fatty acid synthase-catalyzed de novo fatty acid biosynthesis: from anabolic-energy-storage pathway in normal tissues to jack-of-all-trades in cancer cells. Arch Immunol Ther Exp (Warsz) 2004 52(6):414-426

34. Menendez JA, Lupu R, Colomer R: Targeting fatty acid synthase: potential for therapeutic intervention in her-2/neu-overexpressing breast cancer. Drug News Perspect 2005, 18(6):375-385.

35. Jin Q, Yuan LX, Boulbes D, Baek JM, Wang YN, Gomez-Cabello D, Hawke DH, Yeung SC, Lee MH, Hortobagyi GN, et al: Fatty acid synthase phosphorylation: a novel therapeutic target in HER2-overexpressing breast cancer cells. Breast Canc Res 2010, 12(6):R96.

36. Liang YC, Lin-shiau SY, Chen CF, Lin JK: Suppression of extracellular signals and cell proliferation through EGF receptor binding by (-)-epigallocatechin gallate in human A431 epidermoid carcinoma cells. J Cell Biochem 1997, 67(1):55-65.

37. Shimizu M, Deguchi A, Joe AK, Mckoy JF, Moriwaki H, Weinstein IB: EGCG inhibits activation of HER3 and expression of cyclooxygenase-2 in human colon cancer cells. J Exp Ther Oncol 2005, 5(1):69-78.

38. Shimizu M, Deguchi A, Lim JT, Moriwaki H, Kopelovich L, Weinstein IB: (-)-Epigallocatechin gallate and polyphenon E inhibit growth and activation of the epidermal growth factor receptor and human epidermal growth factor receptor-2 signaling pathways in human colon cancer cells. Clin Cancer Res 2005, 11(7):2735-2746.

39. Lee MJ, Maliakal P, Chen L, Meng X, Bondoc FY, Prabhu S, Lambert G, Mohr $S$, Yang CS: Pharmacokinetics of tea catechins after ingestion of green tea and (-)-epigallocatechin-3-gallate by humans: formation of different metabolites and individual variability. Canc Epidemiol Biomarkers Prev 2002, 11(10 Pt 1):1025-1032

40. Petroulakis E, Mamane $Y$, Le Bacquer O, Shahbazian D, Sonenberg N: mTOR signaling: implications for cancer and anticancer therapy. $\mathrm{Br} J \mathrm{Cancer}$ 2006, 94(2):195-199. 
41. Lin VC, Chou CH, Lin YC, Lin JN, Yu CC, Tang CH, Lin HY, Way TD: Osthole suppresses fatty acid synthase expression in HER2-overexpressing breast cancer cells through modulating Akt/mTOR pathway. J Agric Food Chem 2010, 58(8):4786-4793.

42. Huang CH, Tsai SJ, Wang YJ, Pan MH, Kao JY, Way TD: EGCG inhibits protein synthesis, lipogenesis, and cell cycle progression through activation of AMPK in p53 positive and negative human hepatoma cells. Mol Nutr Food Res 2009, 53(9):1156-1165.

43. Jackowski S, Wang J, Baburina I: Activity of the phosphatidylcholine biosynthetic pathway modulates the distribution of fatty acids into glycerolipids in proliferating cells. Biochim Biophys Acta 2000, 1483(3):301-315.

44. Thupari JN, Landree LE, Ronnett GV, Kuhajda FP: C75 increases peripheral energy utilization and fatty acid oxidation in diet-induced obesity. Proc Natl Acad Sci U S A 2002, 99(14):9498-9502.

doi:10.1186/1471-2407-12-280

Cite this article as: Relat et al:: Different fatty acid metabolism effects of (-)-Epigallocatechin-3-Gallate and C75 in Adenocarcinoma lung cancer. BMC Cancer 2012 12:280.

\section{Submit your next manuscript to BioMed Central and take full advantage of:}

- Convenient online submission

- Thorough peer review

- No space constraints or color figure charges

- Immediate publication on acceptance

- Inclusion in PubMed, CAS, Scopus and Google Scholar

- Research which is freely available for redistribution 